\title{
Emergence and Spreading Potential of Zika Virus
}

\author{
Álvaro Fajardo, Juan Cristina and Pilar Moreno* \\ Laboratorio de Virología Molecular, Centro de Investigaciones Nucleares, Facultad de Ciencias, Universidad de la República, \\ Montevideo, Uruguay
}

Zika virus (ZIKV) is an arthropod-borne Flavivirus (family Flaviviridae) closely related to dengue, yellow fever and West Nile viruses. ZIKV remained neglected, confined to enzootic transmission cycles in Africa and Asia, until the first significant outbreak was reported in Micronesia in 2007. Subsequent epidemics of growing incidence occurred in French Polynesia and other South Pacific Islands, and recently, in the Americas. The latter and currently ongoing outbreak of unprecedented incidence revealed the association of ZIKV infection with the occurrence of severe congenital malformations and neurological diseases, leading to a widespread concern about its potential to pose a global public health threat. Serological and molecular data suggest that the genetic and geographic diversification of ZIKV may be greatly underestimated. Here we discuss several ecological and epidemiological aspects, together with the evolutionary processes that may have driven the emergence and abrupt spread of ZIKV in the Americas.

\section{Keywords: ZIKV, emerging infectious diseases, genetic variability ZIKV, molecular evolution, spreading potential} ZIKV

Raul Isea

Fundaciòn Instituto de Estudios

Avanzados, Venezuela Indra Vythilingam,

University of Malaya, Malaysia Sandra Laurence Lopez-Verges, Instituto Conmemorativo Gorgas de Estudios de la Salud, Panama

*Correspondence: Pilar Moreno pmoreno@cin.edu.uy

Specialty section: This article was submitted to Infectious Diseases,

a section of the journal

Frontiers in Microbiology

Received: 31 July 2016 Accepted: 05 October 2016 Published: 20 October 2016

Citation:

Fajardo Á, Cristina $J$ and Moreno $P$ (2016) Emergence and Spreading

Potential of Zika Virus.

Front. Microbiol. 7:1667.

doi: 10.3389/fmicb.2016.01667

\section{INTRODUCTION}

Zika virus (ZIKV) is a mosquito-borne virus that belongs to the Spondweni serocomplex in the Flavivirus genus of the Flaviviridae family. ZIKV is closely related to dengue virus (DENV), yellow fever virus (YFV), and West Nile virus (WNV) (Kuno et al., 1998). Although ZIKV enzootic activity was repeatedly observed in different regions of Africa and Asia, significant human outbreaks have only recently occurred, in particular during current American epidemics (Haddow et al., 2013). Its high variability, great adaptability to vectors and hosts, as well as its association with neurological diseases and fetus malformations, has converted ZIKV in one of the biggest challenges for global health as regards to prevention, detection and prospect for control.

\section{EPIDEMIOLOGY}

Zika virus was first detected in 1947 in rhesus monkeys, during a yellow fever routine surveillance in the Zika Forest in Uganda, where one year later was also isolated from a pool of Aedes africanus mosquitoes (Dick et al., 1952). The first human disease related with ZIKV was reported in 1954 in Nigeria (Macnamara, 1954). ZIKV enzootic activity was repeatedly observed in different regions of Africa and Asia, but only 14 human cases were reported until 2007 (Faye et al., 2014), when the first significant ZIKV outbreak occurred in Yap Island (Micronesia), leading to infection of $73 \%$ of the residents older than 3 years (Duffy et al., 2009). Later on, in 2013, a huge epidemic event occurred 
in French Polynesia with around 30.000 symptomatic cases that included low fever, maculopapular rash, arthralgia and conjunctivitis (Musso et al., 2014). ZIKV outbreaks were subsequently reported in different Pacific islands including New Caledonia, Solomon Islands, Cook Islands, Fiji, Samoa, Vanuatu, and Easter Island (Cao-Lormeau et al., 2014; Dupont-Rouzeyrol et al., 2015; Musso and Gubler, 2016). In March 2015, ZIKV was reported in Salvador, Brazil (Campos et al., 2015; Zanluca et al., 2015), and rapidly spread throughout the Americas, leading to autochthonous cases in 40 countries of this continent by July 7 th, 2016 (PAHO, 2016).

Zika virus ZIKV infections in humans are mainly asymptomatic, causing in some patients a mild, self-limited febrile illness that can be accompanied by other clinical symptoms like rash, arthralgia or conjunctivitis (Simpson, 1964). This was the usual clinical picture until the French Polynesian outbreak in 2013, when severe neurological complications were observed. Epidemiological data from this outbreak documented a 20-fold increase from expected in the incidence of Guillain-Barré syndrome (GBS) (Oehler et al., 2014), as well as meningoencephalitis (Carteaux et al., 2016) and acute myelitis (Mécharles et al., 2016) cases. GBS was also associated with ZIKV infections during current epidemics in the Americas in 12 countries (Dirlikov et al., 2016; dos Santos et al., 2016; PAHO, 2016; Rozé et al., 2016). In addition, the latter outbreak coincided both in time and geographic location with an increase in the number of infants born with microcephaly and other central nervous system malformations (Schuler-Faccini et al., 2016; Ventura et al., 2016). By July 2016, 1.638 cases of congenital syndrome associated with ZIKV infection were confirmed in Brazil, with reported cases of this disorder in Colombia, El Salvador, French Guiana, Martinique, Panama, Puerto Rico, and United States (PAHO, 2016). Subsequent retrospective studies also revealed congenital cerebral malformations in newborns during French Polynesian outbreak of 2013 (Besnard et al., 2016; Cauchemez et al., 2016). Accumulating evidence supports the association between ZIKV infection and birth defects, including the detection of ZIKV RNA, viral particles, and/or viral antigens in placenta, amniotic fluid and fetal tissues, being the latter studies performed on microcephalic fetuses after miscarriage or neonatal death (Calvet et al., 2016; Ladhani et al., 2016; Martines et al., 2016; Meaney-Delman et al., 2016; Mlakar et al., 2016; Oliveira Melo et al., 2016; Rasmussen et al., 2016; Sarno et al., 2016). Moreover, a recent study reports the detection of anti-ZIKV IgM antibodies in cerebrospinal fluids of 30 out of 31 neonates with microcephaly, strongly suggesting a congenital infection with ZIKV (Cordeiro et al., 2016). In addition, experimental data indicated that ZIKV infects human neural progenitor cells attenuating their growth (Hughes et al., 2016; Li et al., 2016; Nguyen et al., 2016; Tang et al., 2016).

As previously discussed, until 2007 our knowledge of this ZIKV was restricted to limited confirmed cases in Africa and Asia. However, on the basis of entomological, epidemiological and seroprevalence studies, it can be deduced that the incidence, prevalence and dispersion of ZIKV have been significantly underestimated (Musso and Gubler, 2016). Human serosurveys suggest that ZIKV might be endemic in most part of Africa and South-East Asia (Dick et al., 1952; Smithburn, 1952, 1954; Hammon et al., 1958; Pond, 1963; Fagbami, 1979; Petersen et al., 2016), although it is important to note that the specificity of the serological studies used is uncertain due to the significant crossreaction between different flaviviruses (Lazear and Diamond, 2016). This silent circulation may be explained by the fact that most ZIKV infections are asymptomatic, and clinical manifestations are generally mild and can be mistaken with other arboviral infections, leading to significant misdiagnosis and underreporting (Haddow et al., 2012). For instance, patients of Micronesian outbreak of 2007 were initially diagnosed with dengue fever (Lanciotti et al., 2008; Duffy et al., 2009). The same happens in most tropical and subtropical regions where other non-specific diseases like dengue and/or chikungunya are endemic (Nhan and Musso, 2015). Moreover, as ZIKV is not commonly tested in routine diagnostic assays, a considerable number of cases are expected to remain undetected. For example, recently retrospective analyses revealed a widespread distribution of ZIKV in Thailand (Buathong et al., 2015), as was previously suggested by the confirmation of imported cases from travelers returning from that country (Fonseca et al., 2014; Tappe et al., 2014). Several other reports of imported cases from tourists that have visited different Asian and South Pacific Islands reveal that circulation of ZIKV remain silent in different countries (Deng et al., 2016; Korhonen et al., 2016; Zhang et al., 2016).

\section{TRANSMISSION}

Zika virus circulation has been mainly reported in sylvatic enzootic transmission cycles, involving arboreal mosquitos and non-human primates (Darwish et al., 1983; Hayes, 2009; Faye et al., 2014). Several mosquitoes species have been related with African and Asian jungle cycles, especially A. africanus (Dick et al., 1952; Haddow et al., 1964; Berthet et al., 2014; Diallo et al., 2014), as well as other Aedes spp. mosquitoes (Marchette et al., 1969; Cornet et al., 1979b; Fagbami, 1979; McCrae and Kirya, 1982; Akoua-Koffi et al., 2001; Berthet et al., 2014; Diallo et al., 2014). In enzootic transmission cycles, humans and other mammals may act as occasional dead-end hosts (Kenney and Brault, 2014). ZIKV antibodies have been detected in several vertebrates (Darwish et al., 1983; Haddow et al., 2012), suggesting that other animals may be involved in natural transmission cycles.

Humans accidentally infected may potentially act as hosts leading to urban cycles, if they exhibit high and sustainable viremia (Kuno and Chang, 2005; Duffy et al., 2009). The role of a bridge vector between both ecologically distinct transmission cycles is essential for these events to occur. Several mosquito species have been studied in terms of their host choice to evaluate their potential as bridge vectors of different arboviruses (Kaddumukasa et al., 2015). A. vittatus have been suggested to link both ZIKV cycles in Africa (Diallo et al., 2014). A. albopictus was found to be implicated in DENV cycle switching in Asia (Vasilakis et al., 2011; Hanley et al., 2013), and therefore, it is likely to play the same role with ZIKV. Moreover, experimental data have shown $A$. albopictus adaptability to transmit ZIKV 
(Wong et al., 2013; Chouin-Carneiro et al., 2016; Di Luca et al., 2016), as has been observed at least in Gabon in 2007 (Grard et al., 2014). However, A. aegypti seems to have the highest vectorial capacity in urban cycles (Lord et al., 2015), and has been related with most human outbreaks, including current American epidemics (Boorman and Porterfield, 1956; Marchette et al., 1969; Cornet et al., 1979a; Olson et al., 1981; Li et al., 2012; Weaver et al., 2016). Both A. aegypti and A. albopictus are anthropophilic mosquitoes that are widely distributed throughout tropical and subtropical regions and are also competent vectors for other arboviruses like DENV, YFV and chikungunya virus (CHIKV) (Musso and Gubler, 2016). Other mosquito species, like $A$. hensilli and A. polynesiensis, have been, respectively, responsible for ZIKV outbreaks in Yap Island in 2007 (Ledermann et al., 2014) and French Polynesia in 20132014 (Musso et al., 2014), suggesting that the potential role of other Aedes spp. as additional vectors should not be ruled out.

Although mosquito-borne transmission is the most common route for ZIKV infection, current South Pacific/American outbreaks revealed other modes of biological transmission. In particular, the elevated number of newborns with microcephaly raised concern about maternal-fetal transmission during pregnancy. As previously discussed, growing evidence support trans-placental transmission, and perinatal transmission of ZIKV has also been reported in French Polynesia (Besnard et al., 2014). Furthermore, recent studies have demonstrated that ZIKV RNA can be found in semen 62 and 93 days after onset of symptoms, although virus infectivity was not tested as cell culture assays were not performed (Atkinson et al., 2016; Mansuy et al., 2016). This finding is in line with the amount of sexually transmitted cases that have been lately reported (Musso et al., 2015; Deckard et al., 2016; D'Ortenzio et al., 2016; Frank et al., 2016; Hills et al., 2016; Turmel et al., 2016; Venturi et al., 2016). Moreover, recently published data suggest the first case of female to male sexual transmission (Davidson et al., 2016). Despite the potential of sexual transmission to promote an epidemic has been predicted to be unlikely (Yakob et al., 2016), these findings indicate that this route of transmission may contribute to dispersal of ZIKV greater than initially thought.

\section{GENETIC VARIABILITY OF ZIKV}

Zika virus is a single-stranded, positive sense, RNA virus with a genome of approximately 10,794 nt in length. Its genome carries a single open reading frame (ORF) that encodes three structural (capsid (C), precursor of membrane (prM) and envelope (E)) and seven non-structural (NS) proteins, with 2 flanking noncoding regions ( $5^{\prime}$ and $3^{\prime}$ NCR) (Kuno and Chang, 2007). Several phylogenetic analyses have been performed in order to investigate the genetic diversity of ZIKV, using both partial and complete genome regions (Lanciotti et al., 2008; Haddow et al., 2012; Faye et al., 2014; Enfissi et al., 2016; Fajardo et al., 2016; Faria et al., 2016; Gong et al., 2016; Shen et al., 2016; Wang et al., 2016). Fulllength ORF sequences analyses reveal that the high error rate of RNA-dependent RNA polymerase has driven ZIKV to evolve into two different genetic groups, denominated African and AsianAmerican lineages (see Figure 1) (Haddow et al., 2012; Enfissi et al., 2016; Faria et al., 2016).

African lineage comprises strains isolated in Burkina Faso, Central African Republic, Cote d'Ivoire, Gabon, Nigeria, Senegal, and Uganda, and can be further divided in two sub-lineages, as was indicated by phylogenetic approaches restricted to RNApolymerase (NS5) (Lanciotti et al., 2008) or E (Faye et al., 2014) coding regions. On the basis of phylodynamic studies, Faye et al. (2014) suggested that the most common recent ancestor of all reported ZIKV strains circulated around 1920 in Uganda, from where it spread to West Africa and afterward to Malaysia, giving rise to Asian (currently Asian-American) lineage (Faye et al., 2014). This genetic group has been better characterized, especially after current epidemics when several full-length sequences were obtained. This lineage clusters together ancestral Malaysian strains (1966) with variants from Micronesia (2007), Cambodia (2010), Philippines (2012), Thailand (2014), and all ZIKV strains reported in the ongoing American outbreak (Figure 1, in blue), which are closely related to French Polynesian variants of ZIKV epidemics of 2013. Recent studies indicated that currently ZIKV strains circulating in the Americas emerged from a single introduction of an ancestor that existed in French Polynesia between August 2013 and June 2014 (Fajardo et al., 2016; Faria et al., 2016). This hypothesis is in line with observed phylogenetic patterns, as French Polynesian variant roots the American cluster (Figure 1). However, seven variants recently obtained from Chinese travelers returning from Fiji and Samoa (Figure 1, in red), share a different evolutionary history, revealing that two different sub-lineages are responsible of current ZIKV epidemics in the Americas and in South Pacific Islands (Deng et al., 2016; Zhang et al., 2016). Moreover, a recent study indicated that these imported Chinese strains share an ancestor with American variants that circulated around May 2013 (Fajardo et al., 2016), coinciding with the time when the ancestor of all American isolates was circulating (Faria et al., 2016). This finding indicates that two different evolutionary routes were followed by ancestral strains that emerged in French Polynesia, giving rise to different contemporaneous sub-lineages circulating in the Americas and in South Pacific Islands, revealing that ZIKV diversification may be greatly underestimated (Fajardo et al., 2016).

Unfortunately, there are no other full-length sequences available from the Pacific Islands outbreak, which limits our interpretation of the evolutionary patterns, diversity and pathogenicity of currently circulating ZIKV strains. In fact, the lack of complete genome sequences distributed over time and space has been one of the major historical limitations to explore in detail the phylogenetic relationships of ZIKV variants and their spatio-temporal distribution. For instance, recent reports have suggested that another genetic group, African lineage II, is revealed when phylogenetic relationships are deduced through the analysis of E and NS5 coding regions (Gong et al., 2016; Shen et al., 2016). This lineage group together one variant of Cote d'Ivoire of 1980 and six strains isolated in Senegal between 1998 and 2001 (Faye et al., 2014). Furthermore, both African and Asian-American clusters seem to be rooted by this lineage, which also suggests a greater ZIKV genetic and geographic 


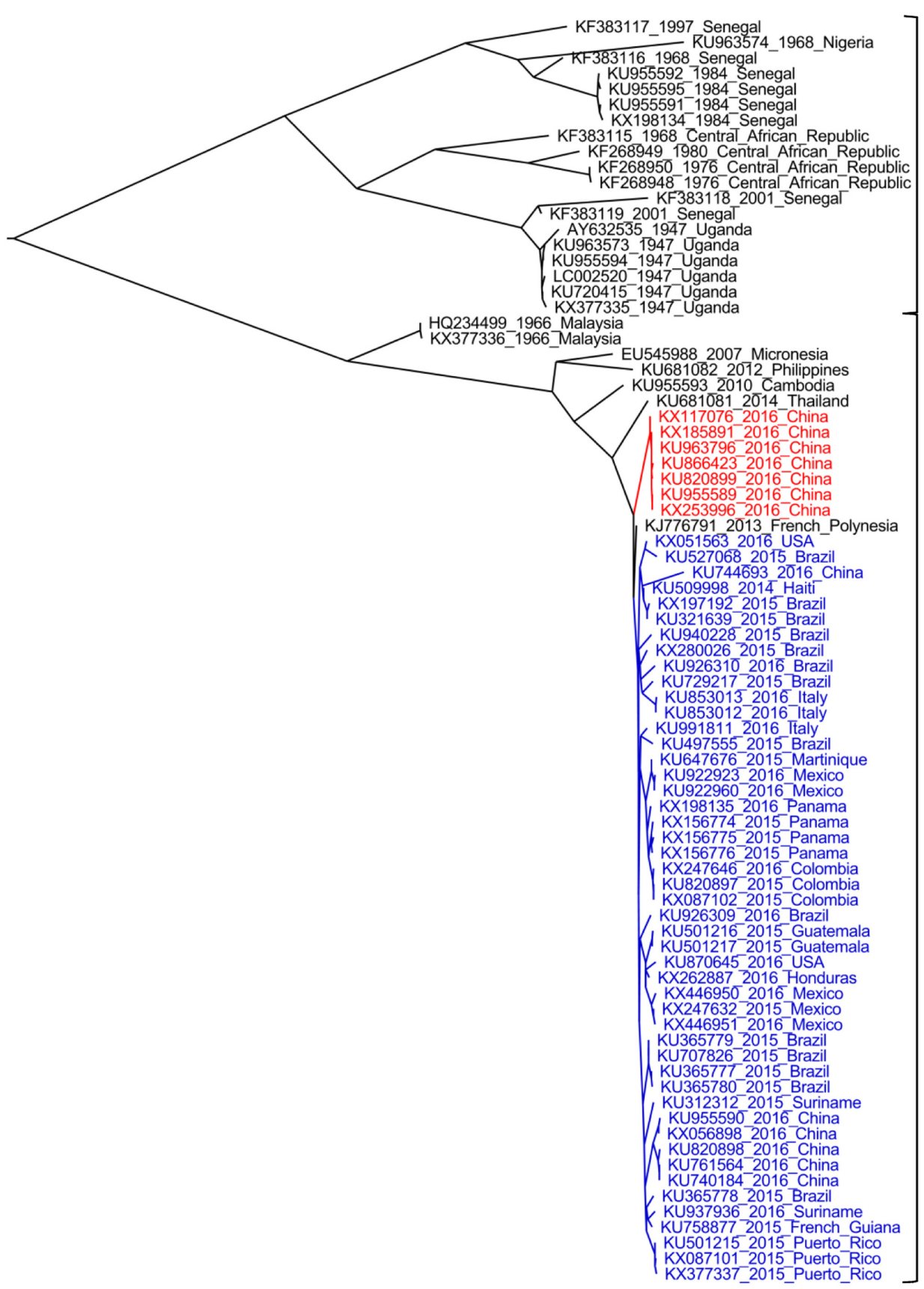

\section{African lineage}

\section{Asian-American lineage}

FIGURE 1 | Maximum-likelihood analysis of all complete ORF sequences of Zika virus (ZIKV) available. The phylogenetic tree was performed using PhyML software (Guindon et al., 2005) under a GTR+G+I substitution model, and edited with FigTree program v1.4.2 (available at: http://tree.bio.ed.ac.uk). Strains are indicated by their accession number, year and country of isolation. Sequences derived from variants isolated during current American outbreak and from imported strains from Fiji and Samoa (Deng et al., 2016; Zhang et al., 2016), are indicated in blue and red, respectively. Bootstrap values >90\% support major nodes but are not shown for visualization purpose. The bar at the bottom of the tree denotes nucleotide distance.

diversification than expected (Shen et al., 2016). This hypothesis was also supported by Gong et al., who calculated a genetic distance of 0.212 substitutions/site between the $\mathrm{E}$ gene of two contemporary isolates of Senegal, belonging to African lineages I and II, respectively. Considering evolutionary rates of the order of $10^{-3}$ substitutions/site/year, as recently estimated for American ZIKV strains (Fajardo et al., 2016; Faria et al., 2016), ZIKV may have been circulating in Africa for more than 100 years 
(Gong et al., 2016). Therefore, the genetic characterization of variants of this lineage would provide essential information to investigate the origin, geographic dispersion and genetic diversity of ZIKV.

\section{ZIKV SPREADING POTENTIAL}

The emergence and dispersal of ZIKV in the Americas reminds us of the route that was previously followed by other arboviruses, like DENV and CHIKV, which were first detected in Africa, and spread subsequently to Asia and the Americas. This migration pattern is associated with ZIKV capacity to adapt to urban vectors, like $A$. aegypti, which allows its expansion into human environments. A general characteristic that is shared between different arboviruses is their high mutation rates, which provide them with the possibility to explore different phenotypical changes in their continually evolving process to adapt to different vectors and hosts (Kuno and Chang, 2005). For instance, a single amino acid change in its surface glycoprotein allows CHIKV to switch its competent vector to A. albopictus (Tsetsarkin et al., 2007). Therefore, genetic changes play a major role in adaptation of arboviruses to different hosts and vectors, as has been also reported in DENV (Messer et al., 2003; Bennett et al., 2010) and WNV (Malkinson et al., 2002; Brault et al., 2007; Moudy et al., 2007).

The recent epidemics in South Pacific and the Americas with its unprecedented association with microcephaly and GBS cases, led to the proposal of different hypothesis to explain this emergence. It is likely that as a consequence of different genetic changes, ancestral Asian lineage gave rise to epidemic strains that become better adapted to humans, leading to infections with higher viremia levels, enhancing trans-placental transmission and modulating changes in cell tropism (Musso and Gubler, 2016; Weaver et al., 2016). Moreover, recent analyses have suggested a bias in the codon usage of ZIKV to increase its fitness in humans (Freire et al., 2015; Cristina et al., 2016; Russell, 2016). This hypothesis is supported by the shortterm diversification observed among recent isolates (Figure 1), revealing the expansion of ZIKV into a large naïve population (Weaver et al., 2016). It has also been hypothesized that the rare congenital malformations and immunological disorders may be in fact low frequency events in ZIKV infections, that are now exposed due to the extent of recent outbreaks (Musso and Gubler, 2016). Furthermore, recent studies have suggested that pre-existing DENV antibodies may enhance

\section{REFERENCES}

Akoua-Koffi, C., Diarrassouba, S., Bénié, V. B., Ngbichi, J. M., Bozoua, T., Bosson, A., et al. (2001). [Investigation surrounding a fatal case of yellow fever in Côte d'Ivoire in 1999]. Bull. Soc. Pathol. Exot. 94, 227-230.

Atkinson, B., Hearn, P., Afrough, B., Lumley, S., Carter, D., Aarons, E. J., et al. (2016). Detection of Zika virus in semen. Emerg. Infect. Dis. 22:940. doi: 10.3201/eid2205.160107
ZIKV infection through an antibody-dependent enhancement mechanism, similar to what happens in secondary infections of DENV (Dejnirattisai et al., 2016; Paul et al., 2016). If this is confirmed it would have huge implications for disease pathogenesis, considering that current epidemics are occurring in regions where most of the population has already been exposed to DENV. Additionally, this mechanism of infection enhancement, together with ZIKV adaptability to vectors/hosts, the widely distribution of competent mosquitoes and the unusual non-vectorial human-to-human transmission routes observed, can help to interpret the reasons for the suddenly explosive emergence of ZIKV in the Americas and its potential to spread into other geographic regions.

\section{CONCLUSIONS}

Current ZIKV epidemics occurring throughout the American continent represent the most recent example of a mosquitoborne virus introduction into previously unaffected areas with immunologically naïve population. This unexpected emergence follows recent arrival and spreading of DENV, WNV, and CHIKV, which clearly responds to human activities that promotes optimal ecological environments for vectorial activity. Although ZIKV has remained almost ignored for half a century, entomological, epidemiological and molecular studies have strongly indicated that its incidence, geographic dispersion and genetic diversity have been significantly underestimated. Its adaptability to different mosquito species allowed ZIKV to spread into efficient urban transmission cycles helped by the widespread distribution of competent vectors. Furthermore, unprecedented routes of transmission for flaviviruses, including maternal-fetal and sexual intercourse, may contribute to increase its spreading potential.

\section{AUTHOR CONTRIBUTIONS}

AF, JC, and PM contributed to the elaboration or this minireview. All authors read and approved the final manuscript.

\section{ACKNOWLEDGMENTS}

This work was supported by: Comisión Sectorial de Investigación Científica (CSIC), UdelaR, Uruguay; Agencia Nacional de Investigación e Innovación (ANII); and Programa de Desarrollo de las Ciencias Básicas (PEDECIBA).

Bennett, S. N., Drummond, A. J., Kapan, D. D., Suchard, M. A., Muñoz-Jordán, J. L., Pybus, O. G., et al. (2010). Epidemic dynamics revealed in dengue evolution. Mol. Biol. Evol. 27, 811-818. doi: 10.1093/molbev/msp285

Berthet, N., Nakouné, E., Kamgang, B., Selekon, B., Descorps-Declère, S., Gessain, A., et al. (2014). Molecular characterization of three Zika flaviviruses obtained from sylvatic mosquitoes in the Central African Republic. Vector Borne Zoonotic Dis. 14, 862-865. doi: 10.1089/vbz.2014. 1607 
Besnard, M., Eyrolle-Guignot, D., Guillemette-Artur, P., Lastère, S., BostBezeaud, F., Marcelis, L., et al. (2016). Congenital cerebral malformations and dysfunction in fetuses and newborns following the 2013 to 2014 Zika virus epidemic in French Polynesia. Euro Surveill. 21. doi: 10.2807/15607917.ES.2016.21.13.30181

Besnard, M., Lastere, S., Teissier, A., Cao-Lormeau, V., and Musso, D. (2014). Evidence of perinatal transmission of Zika virus, French Polynesia, December 2013 and February 2014. Euro Surveill. 19.

Boorman, J. P., and Porterfield, J. S. (1956). A simple technique for infection of mosquitoes with viruses; transmission of Zika virus. Trans. R. Soc. Trop. Med. Hyg. 50, 238-242. doi: 10.1016/0035-9203(56)90029-3

Brault, A. C., Huang, C. Y.-H., Langevin, S. A., Kinney, R. M., Bowen, R. A., Ramey, W. N., et al. (2007). A single positively selected West Nile viral mutation confers increased virogenesis in American crows. Nat. Genet. 39, 1162-1166. doi: $10.1038 / \mathrm{ng} 2097$

Buathong, R., Hermann, L., Thaisomboonsuk, B., Rutvisuttinunt, W., Klungthong, C., Chinnawirotpisan, P., et al. (2015). Detection of Zika Virus Infection in Thailand, 2012-2014. Am. J. Trop. Med. Hyg. 93, 380-383. doi: 10.4269/ajtmh.15-0022

Calvet, G., Aguiar, R. S., Melo, A. S. O., Sampaio, S. A., de Filippis, I., Fabri, A., et al. (2016). Detection and sequencing of Zika virus from amniotic fluid of fetuses with microcephaly in Brazil: a case study. Lancet Infect. Dis. 16, 653-660. doi: 10.1016/S1473-3099(16)00095-5

Campos, G. S., Bandeira, A. C., and Sardi, S. I. (2015). Zika virus outbreak, Bahia, Brazil. Emerg. Infect. Dis. 21, 1885-1886. doi: 10.3201/eid2110.150847

Cao-Lormeau, V.-M., Roche, C., Teissier, A., Robin, E., Berry, A.-L., Mallet, H.-P., et al. (2014). Zika virus, French polynesia, South pacific, 2013. Emerg. Infect. Dis. 20, 1085-1086. doi: 10.3201/eid2006.140138

Carteaux, G., Maquart, M., Bedet, A., Contou, D., Brugières, P., Fourati, S., et al. (2016). Zika virus associated with meningoencephalitis. N. Engl. J. Med. 374, 1595-1596. doi: 10.1056/NEJMc1602964

Cauchemez, S., Besnard, M., Bompard, P., Dub, T., Guillemette-Artur, P., EyrolleGuignot, D., et al. (2016). Association between Zika virus and microcephaly in French Polynesia, 2013-15: a retrospective study. Lancet 387, 2125-2132. doi: 10.1016/S0140-6736(16)00651-6

Chouin-Carneiro, T., Vega-Rua, A., Vazeille, M., Yebakima, A., Girod, R., Goindin, D., et al. (2016). Differential Susceptibilities of Aedes aegypti and Aedes albopictus from the Americas to Zika Virus. PLoS Negl. Trop. Dis. 10:e0004543. doi: 10.1371/journal.pntd.0004543

Cordeiro, M. T., Pena, L. J., Brito, C. A., Gil, L. H., Marques, E. T., et al. (2016). Positive IgM for Zika virus in the cerebrospinal fluid of 30 neonates with microcephaly in Brazil. Lancet 387, 1811-1812. doi: 10.1016/S01406736(16)30253-7

Cornet, M., Robin, Y., Adam, C., Valade, M., and Calvo, M. A. (1979a). Comparison between experimental transmission of yellow fever and Zika viruses in Aedes aegypti [arbovirus diseases, Ethiopian region, Senegal]. Cah. Ser. Entomol. Med. Parasitol. 27, 47-53.

Cornet, M., Robin, Y., Chateau, R., Hème, G., Adam, C., Valade, M., et al. (1979b). Isolements d'arbovirus au Sénégal oriental à partir de moustiques (1972-1977) et notes sur l'épidémiologie des virus transmis par les Aedes, en particulier du virus amaril. Cah. ORSTOM. Série Entomol. Médicale Parasitol. 17, 149-163.

Cristina, J., Fajardo, A., Soñora, M., Moratorio, G., and Musto, H. (2016). A detailed comparative analysis of codon usage bias in Zika virus. Virus Res. 223, 147-152. doi: 10.1016/j.virusres.2016.06.022

Darwish, M. A., Hoogstraal, H., Roberts, T. J., Ahmed, I. P., and Omar, F. (1983). A sero-epidemiological survey for certain arboviruses (Togaviridae) in Pakistan. Trans. R. Soc. Trop. Med. Hyg. 77, 442-445. doi: 10.1016/00359203(83)90106-2

Davidson, A., Slavinski, S., Komoto, K., Rakeman, J., and Weiss, D. (2016). Suspected Female-to-Male Sexual Transmission of Zika Virus New York City, 2016. MMWR. Morb. Mortal. Wkly. Rep. 65, 716-717. doi: 10.15585/mmwr.mm6528e2

Deckard, D. T., Chung, W. M., Brooks, J. T., Smith, J. C., Woldai, S., Hennessey, M., et al. (2016). Male-to-Male Sexual Transmission of Zika Virus - Texas, January 2016. MMWR. Morb. Mortal. Wkly. Rep. 65, 372-374. doi: 10.15585/mmwr.mm6514a3

Dejnirattisai, W., Supasa, P., Wongwiwat, W., Rouvinski, A., Barba-Spaeth, G., Duangchinda, T., et al. (2016). Dengue virus sero-cross-reactivity drives antibody-dependent enhancement of infection with zika virus. Nat. Immunol. 17, 1102-1108. doi: 10.1038/ni.3515

Deng, C., Liu, S., Zhang, Q., Xu, M., Zhang, H., Gu, D., et al. (2016). Isolation and characterization of Zika virus imported to China using C6/36 mosquito cells. Virol. Sin. 31, 176-179. doi: 10.1007/s12250-016-3778-5

Di Luca, M., Severini, F., Toma, L., Boccolini, D., Romi, R., Remoli, M. E., et al. (2016). Experimental studies of susceptibility of Italian Aedes albopictus to Zika virus. Euro Surveill. 21. doi: 10.2807/1560-7917.ES.2016.21.18.30223

Diallo, D., Sall, A. A., Diagne, C. T., Faye, O., Faye, O., Ba, Y., et al. (2014). Zika virus emergence in mosquitoes in Southeastern Senegal, 2011. PLoS ONE 9:e109442. doi: 10.1371/journal.pone.0109442

Dick, G. W. A., Kitchen, S. F., and Haddow, A. J. (1952). Zika virus. I. Isolations and serological specificity. Trans. R. Soc. Trop. Med. Hyg. 46, 509-520. doi: 10.1016/0035-9203(52)90042-4

Dirlikov, E., Major, C. G., Mayshack, M., Medina, N., Matos, D., Ryff, K. R., et al. (2016). Guillain-Barré syndrome during ongoing Zika virus transmission Puerto Rico, January 1-July 31, 2016. MMWR. Morb. Mortal. Wkly. Rep. 65, 910-914. doi: 10.15585/mmwr.mm6534e1

D’Ortenzio, E., Matheron, S., Yazdanpanah, Y., de Lamballerie, X., Hubert, B., Piorkowski, G., et al. (2016). Evidence of sexual transmission of Zika Virus. N. Engl. J. Med. 374, 2195-2198. doi: 10.1056/NEJMc1604449

dos Santos, T., Rodriguez, A., Almiron, M., Sanhueza, A., Ramon, P., de Oliveira, W. K., et al. (2016). Zika virus and the Guillain-Barré syndrome - case series from seven countries. N. Engl. J. Med. doi: 10.1056/NEJMc1609015

Duffy, M. R., Chen, T.-H., Hancock, W. T., Powers, A. M., Kool, J. L., Lanciotti, R. S., et al. (2009). Zika virus outbreak on Yap Island, Federated States of Micronesia. N. Engl. J. Med. 360, 2536-2543. doi: 10.1056/NEJMoa0805715

Dupont-Rouzeyrol, M., O’Connor, O., Calvez, E., Daurès, M., John, M., Grangeon, J.-P., et al. (2015). Co-infection with Zika and dengue viruses in 2 patients, New Caledonia, 2014. Emerg. Infect. Dis. 21, 381-382. doi: 10.3201/eid2102. 141553

Enfissi, A., Codrington, J., Roosblad, J., Kazanji, M., Rousset, D., Lanciotti, R., et al. (2016). Zika virus genome from the Americas. Lancet 387, 227-228. doi: 10.1016/S0140-6736(16)00003-9

Fagbami, A. H. (1979). Zika virus infections in Nigeria: virological and seroepidemiological investigations in Oyo State. J. Hyg. (Lond). 83, 213-219. doi: 10.1017/S0022172400025997

Fajardo, A., Soñora, M., Moreno, P., Moratorio, G., and Cristina, J. (2016). Bayesian coalescent inference reveals high evolutionary rates and diversification of Zika virus populations. J. Med. Virol 88, 1672-1676. doi: 10.1002/jmv.24596

Faria, N. R., Azevedo, R., do, S., da, S., Kraemer, M. U. G., Souza, R., et al. (2016). Zika virus in the Americas: early epidemiological and genetic findings. Science 352, 345-349. doi: 10.1126/science.aaf5036

Faye, O., Freire, C. C. M., Iamarino, A., Faye, O., de Oliveira, J. V. C., Diallo, M., et al. (2014). Molecular evolution of Zika virus during its emergence in the 20(th) century. PLoS Negl. Trop. Dis. 8:e2636. doi: 10.1371/journal.pntd.0002636

Fonseca, K., Meatherall, B., Zarra, D., Drebot, M., MacDonald, J., Pabbaraju, K., et al. (2014). First Case of Zika Virus Infection in a Returning Canadian Traveler. Am. J. Trop. Med. Hyg. 91, 1035-1038. doi: 10.4269/ajtmh.14-0151

Frank, C., Cadar, D., Schlaphof, A., Neddersen, N., Günther, S., SchmidtChanasit, J., et al. (2016). Sexual transmission of Zika virus in Germany, April 2016. Euro Surveill. 21. doi: 10.2807/1560-7917.ES.2016.21.23.30252

Freire, C. C., de, M., Iamarino, A., Neto, D. F., de, L., Sall, A. A., et al. (2015). Spread of the pandemic Zika virus lineage is associated with NS1 codon usage adaptation in humans. Cold Spring Harb. Labs J. doi: 10.1101/032839

Gong, Z., Gao, Y., and Han, G.-Z. (2016). Zika virus: two or three lineages? Trends Microbiol. 24, 521-522. doi: 10.1016/j.tim.2016.05.002

Grard, G., Caron, M., Mombo, I. M., Nkoghe, D., Mboui Ondo, S., Jiolle, D., et al. (2014). Zika Virus in Gabon (Central Africa) - 2007: a new threat from Aedes albopictus? PLoS Negl. Trop. Dis. 8:e2681. doi: 10.1371/journal.pntd. 0002681

Guindon, S., Lethiec, F., Duroux, P., and Gascuel, O. (2005). PHYML Online-a web server for fast maximum likelihood-based phylogenetic inference. Nucleic Acids Res. 33, W557-W559. doi: 10.1093/nar/gki352

Haddow, A. D., Guzman, H., Popov, V. L., Wood, T. G., Widen, S. G., Haddow, A. D., et al. (2013). First isolation of Aedes flavivirus in the Western Hemisphere and evidence of vertical transmission in the mosquito 
Aedes (Stegomyia) albopictus (Diptera: Culicidae). Virology 440, 134-139. doi: 10.1016/j.virol.2012.12.008

Haddow, A. D., Schuh, A. J., Yasuda, C. Y., Kasper, M. R., Heang, V., Huy, R., et al. (2012). Genetic characterization of Zika virus strains: geographic expansion of the Asian lineage. PLoS Negl. Trop. Dis. 6:e1477. doi: 10.1371/journal.pntd.0001477

Haddow, A. J., Williams, M. C., Woodall, J. P., Simpson, D. I., and Goma, L. K. (1964). Twelve isolations of Zika virus from Aedes (Stegomyia) africanus (theobald) taken in and above a Uganda forest. Bull. World Health Organ. 31, 57-69.

Hammon, W. M., Schrack, W. D., and Sather, G. E. (1958). Serological survey for a arthropod-borne virus infections in the Philippines. Am. J. Trop. Med. Hyg. 7, 323-328.

Hanley, K. A., Monath, T. P., Weaver, S. C., Rossi, S. L., Richman, R. L., and Vasilakis, N. (2013). Fever versus fever: the role of host and vector susceptibility and interspecific competition in shaping the current and future distributions of the sylvatic cycles of dengue virus and yellow fever virus. Infect. Genet. Evol. 19, 292-311. doi: 10.1016/j.meegid.2013.03.008

Hayes, E. B. (2009). Zika virus outside Africa. Emerg. Infect. Dis. 15, 1347-1350. doi: 10.3201/eid1509.090442

Hills, S. L., Russell, K., Hennessey, M., Williams, C., Oster, A. M., Fischer, M., et al. (2016). Transmission of Zika virus through sexual contact with travelers to areas of ongoing transmission - Continental United States, 2016. MMWR. Morb. Mortal. Wkly. Rep. 65, 215-216. doi: 10.15585/mmwr.mm6508e2

Hughes, B. W., Addanki, K. C., Sriskanda, A. N., McLean, E., Bagasra, O., Bearcroft, W. G., et al. (2016). Infectivity of immature neurons to Zika virus: a link to congenital Zika Syndrome. EBiomedicine 10, 442-448. doi: 10.1016/j.ebiom.2016.06.026

Kaddumukasa, A. M., Kayondo, K. J., Masiga, D., Akol, M. A., Lutwama, J. J., and Masembe, C. (2015). High proportion of mosquito vectors in Zika forest, Uganda, feeding on humans has implications for the spread of new arbovirus pathogens. Afr. J. Biotechnol. 14, 1418-1426. doi: 10.5897/AJB2015.14474

Kenney, J. L., and Brault, A. C. (2014). The role of environmental, virological and vector interactions in dictating biological transmission of arthropod-borne viruses by mosquitoes. Adv. Virus Res. 89, 39-83. doi: 10.1016/B978-0-12800172-1.00002-1

Korhonen, E., Huhtamo, E., and Smura, T. (2016). Zika virus infection in a traveller returning from the Maldives, June 2015. Euro Surveill. 21.

Kuno, G., Chang, G. J., Tsuchiya, K. R., Karabatsos, N., and Cropp, C. B. (1998). Phylogeny of the genus Flavivirus. J. Virol. 72, 73-83.

Kuno, G., and Chang, G.-J. J. (2005). Biological transmission of arboviruses: reexamination of and new insights into components, mechanisms, and unique traits as well as their evolutionary trends. Clin. Microbiol. Rev. 18, 608-637. doi: 10.1128/CMR.18.4.608-637.2005

Kuno, G., and Chang, G.-J. J. (2007). Full-length sequencing and genomic characterization of Bagaza, Kedougou, and Zika viruses. Arch. Virol. 152, 687-696. doi: 10.1007/s00705-006-0903-Z

Ladhani, S. N., O'Connor, C., Kirkbride, H., Brooks, T., and Morgan, D. (2016). Outbreak of Zika virus disease in the Americas and the association with microcephaly, congenital malformations and Guillain-Barré syndrome. Arch. Dis. Child. 101, 600-602. doi: 10.1136/archdischild-2016-310590

Lanciotti, R. S., Kosoy, O. L., Laven, J. J., Velez, J. O., Lambert, A. J., Johnson, A. J., et al. (2008). Genetic and serologic properties of Zika virus associated with an epidemic, Yap State, Micronesia, 2007. Emerg. Infect. Dis. 14, 1232-1239. doi: 10.3201/eid1408.080287

Lazear, H. M., and Diamond, M. S. (2016). Zika virus: new clinical syndromes and its emergence in the western hemisphere. J. Virol. 90, 4864-4875. doi: 10.1128/JVI.00252-16

Ledermann, J. P., Guillaumot, L., Yug, L., Saweyog, S. C., Tided, M., Machieng, P., et al. (2014). Aedes hensilli as a potential vector of Chikungunya and Zika viruses. PLoS Negl. Trop. Dis. 8:e3188. doi: 10.1371/journal.pntd. 0003188

Li, C., Xu, D., Ye, Q., Hong, S., Jiang, Y., Liu, X., et al. (2016). Zika virus disrupts neural progenitor development and leads to microcephaly in mice. Cell Stem Cell 19, 120-126. doi: 10.1016/j.stem.2016.04.017

Li, M. I., Wong, P. S. J., Ng, L. C., and Tan, C. H. (2012). Oral Susceptibility of Singapore Aedes (Stegomyia) aegypti (Linnaeus) to Zika Virus. PLoS Negl. Trop. Dis. 6:e1792. doi: 10.1371/journal.pntd.0001792
Lord, J. S., Gurley, E. S., and Pulliam, J. R. C. (2015). Rethinking Japanese Encephalitis virus transmission: a framework for implicating host and vector species. PLoS Negl. Trop. Dis. 9:e0004074. doi: 10.1371/journal.pntd.0004074

Macnamara, F. N. (1954). Zika virus: a report on three cases of human infection during an epidemic of jaundice in Nigeria. Trans. R. Soc. Trop. Med. Hyg. 48, 139-145. doi: 10.1016/0035-9203(54)90006-1

Malkinson, M., Banet, C., Weisman, Y., Pokamunski, S., King, R., Drouet, M.-T., et al. (2002). Introduction of West Nile virus in the Middle East by migrating white storks. Emerg. Infect. Dis. 8, 392-397. doi: 10.3201/eid0804.010217

Mansuy, J. M., Pasquier, C., Daudin, M., Chapuy-Regaud, S., Moinard, N., Chevreau, C., et al. (2016). Zika virus in semen of a patient returning from a non-epidemic area. Lancet Infect. Dis. 16, 894-895. doi: 10.1016/S14733099(16)30153-0

Marchette, N. J., Garcia, R., and Rudnick, A. (1969). Isolation of Zika virus from Aedes aegypti mosquitoes in Malaysia. Am. J. Trop. Med. Hyg. 18, 411-415.

Martines, R. B., Bhatnagar, J., Keating, M. K., Silva-Flannery, L., Muehlenbachs, A., Gary, J., et al. (2016). Notes from the field: evidence of Zika virus infection in brain and placental tissues from two congenitally infected newborns and two fetal losses-Brazil, 2015. MMWR. Morb. Mortal. Wkly. Rep. 65, 159-160. doi: 10.15585/mmwr.mm6506e1

McCrae, A. W., and Kirya, B. G. (1982). Yellow fever and Zika virus epizootics and enzootics in Uganda. Trans. R. Soc. Trop. Med. Hyg. 76, 552-562. doi: 10.1016/0035-9203(82)90161-4

Meaney-Delman, D., Hills, S. L., Williams, C., Galang, R. R., Iyengar, P., Hennenfent, A. K., et al. (2016). Zika virus infection among U.S. Pregnant Travelers-August 2015-February 2016. MMWR. Morb. Mortal. Wkly. Rep. 65, 211-214. doi: 10.15585/mmwr.mm6508e1

Mécharles, S., Herrmann, C., Poullain, P., Tran, T.-H., Deschamps, N., Mathon, G., et al. (2016). Acute myelitis due to Zika virus infection. Lancet 387:1481. doi: 10.1016/S0140-6736(16)00644-9

Messer, W., Gubler, D., Harris, E., Sivananthan, K., and de Silva, A. M. (2003). Emergence and global spread of a dengue serotype 3, subtype III virus. Emerg. Infect. Dis. 9, 800-809.

Mlakar, J., Korva, M., Tul, N., Popović, M., Polǰ̌ak-Prijatelj, M., Mraz, J., et al. (2016). Zika virus associated with microcephaly. N. Engl. J. Med. 374, 951-958. doi: 10.1056/NEJMoa1600651

Moudy, R. M., Meola, M. A., Morin, L.-L. L., Ebel, G. D., and Kramer, L. D. (2007). A newly emergent genotype of West Nile virus is transmitted earlier and more efficiently by Culex mosquitoes. Am. J. Trop. Med. Hyg. 77, 365-370.

Musso, D., and Gubler, D. J. (2016). Zika virus. Clin. Microbiol. Rev. 29, 487-524. doi: 10.1128/CMR.00072-15

Musso, D., Nilles, E. J., Cao-Lormeau, V.-M., Kirya, B., Duffy, M., Chen, T., et al. (2014). Rapid spread of emerging Zika virus in the Pacific area. Clin. Microbiol. Infect. 20, O595-O596. doi: 10.1111/1469-0691.12707

Musso, D., Roche, C., Robin, E., Nhan, T., Teissier, A., and Cao-Lormeau, V.M. (2015). Potential sexual transmission of Zika virus. Emerg. Infect. Dis. 21, 359-361. doi: 10.3201/eid2102.141363

Nguyen, H. N., Qian, X., Song, H., and Ming, G. (2016). Neural stem cells attacked by Zika virus. Cell Res. 26, 753-754. doi: 10.1038/cr.2016.68

Nhan, T.-X., and Musso, D. (2015). Emergence of Zika virus. Virologie 19, 225-235. doi: 10.1684 /VIR.2015.0622

Oehler, E., Watrin, L., Larre, P., Leparc-Goffart, I., Lastere, S., Valour, F., et al. (2014). Zika virus infection complicated by Guillain-Barre syndrome-case report, French Polynesia, December 2013. Euro Surveill. 19.

Oliveira Melo, A. S., Malinger, G., Ximenes, R., Szejnfeld, P. O., Alves Sampaio, S., and Bispo de Filippis, A. M. (2016). Zika virus intrauterine infection causes fetal brain abnormality and microcephaly: tip of the iceberg? Ultrasound Obstet. Gynecol. 47, 6-7. doi: 10.1002/uog.15831

Olson, J. G., Ksiazek, T. G., Suhandiman, and Triwibowo. (1981). Zika virus, a cause of fever in Central Java, Indonesia. Trans. R. Soc. Trop. Med. Hyg. 75, 389-393. doi: 10.1016/0035-9203(81)90100-0

PAHO (2016). Zika - Actualización Epidemiológica Regional de la OPS (Américas) - 7 de julio de 2016. Available at: http://www.paho.org/hq/index.php?option= $\mathrm{com}_{\mathrm{c}}$ ontent\&view=article\&id=11599:regional-zika-epidemiological- update - americas\&Itemid $=41691$ \&lang $=\mathrm{es}$

Paul, L. M., Carlin, E. R., Jenkins, M. M., Tan, A. L., Barcellona, C. M., Nicholson, C. O., et al. (2016). Dengue virus antibodies enhance Zika virus infection. Cold Spring Harb. Labs J. doi: 10.1101/050112 
Petersen, L. R., Jamieson, D. J., Powers, A. M., and Honein, M. A. (2016). Zika Virus. N. Engl. J. Med. 374, 1552-1563. doi: 10.1056/NEJMral 602113

Pond, W. L. (1963). Arthropod-borne virus antibodies in sera from residents of South-East Asia. Trans. R. Soc. Trop. Med. Hyg. 57, 364-371. doi: 10.1016/00359203(63)90100-7

Rasmussen, S. A., Jamieson, D. J., Honein, M. A., and Petersen, L. R. (2016). Zika virus and birth defects - reviewing the evidence for causality. N. Engl. J. Med. 374, 1981-1987. doi: 10.1056/NEJMsr1604338

Rozé, B., Najioullah, F., Fergé, J.-L., Apetse, K., Brouste, Y., Cesaire, R., et al. (2016). Zika virus detection in urine from patients with Guillain-Barré syndrome on Martinique, January 2016. Euro Surveill. 21. doi: 10.2807/15607917.ES.2016.21.9.30154

Russell, P. K. (2016). The Zika Pandemic - a perfect storm? PLoS Negl. Trop. Dis. 10:e0004589. doi: 10.1371/journal.pntd.0004589

Sarno, M., Sacramento, G. A., Khouri, R., do Rosário, M. S., Costa, F., Archanjo, G., et al. (2016). Zika virus infection and stillbirths: a case of hydrops fetalis, hydranencephaly and fetal demise. PLoS Negl. Trop. Dis. 10:e0004517. doi: 10.1371/journal.pntd.0004517

Schuler-Faccini, L., Ribeiro, E. M., Feitosa, I. M. L., Horovitz, D. D. G., Cavalcanti, D. P., Pessoa, A., et al. (2016). Possible association between Zika virus infection and microcephaly - Brazil, 2015. MMWR. Morb. Mortal. Wkly. Rep. 65, 59-62. doi: 10.15585/mmwr.mm6503e2

Shen, S., Shi, J., Wang, J., Tang, S., Wang, H., Hu, Z., et al. (2016). Phylogenetic analysis revealed the central roles of two African countries in the evolution and worldwide spread of Zika virus. Virol. Sin. 31, 118-130. doi: 10.1007/s12250016-3774-9

Simpson, D. I. (1964). Zika virus infection in man. Trans. R. Soc. Trop. Med. Hyg. 58, 335-338. doi: 10.1016/0035-9203(64)90201-9

Smithburn, K. C. (1952). Neutralizing antibodies against certain recently isolated viruses in the sera of human beings residing in East Africa. J. Immunol. 69, 223-234.

Smithburn, K. C. (1954). Neutralizing antibodies against arthropod-borne viruses in the sera of long-time residents of Malaya and Borneo. Am. J. Hyg. 59, 157-163.

Tang, H., Hammack, C., Ogden, S. C., Wen, Z., Qian, X., Li, Y., et al. (2016). Zika virus infects human cortical neural progenitors and attenuates their growth. Cell Stem Cell 18, 587-590. doi: 10.1016/j.stem.2016.02.016

Tappe, D., Rissland, J., Gabriel, M., Emmerich, P., Gunther, S., Held, G., et al. (2014). First case of laboratory-confirmed Zika virus infection imported into Europe, November 2013. Euro Surveill. 19.

Tsetsarkin, K. A., Vanlandingham, D. L., McGee, C. E., and Higgs, S. (2007). A single mutation in chikungunya virus affects vector specificity and epidemic potential. PLoS Pathog. 3:e201. doi: 10.1371/journal.ppat. 0030201
Turmel, J. M., Abgueguen, P., Hubert, B., Vandamme, Y. M., Maquart, M., Le Guillou-Guillemette, H., et al. (2016). Late sexual transmission of Zika virus related to persistence in the semen. Lancet 387:2501. doi: 10.1016/S01406736(16)30775-9

Vasilakis, N., Cardosa, J., Hanley, K. A., Holmes, E. C., and Weaver, S. C. (2011). Fever from the forest: prospects for the continued emergence of sylvatic dengue virus and its impact on public health. Nat. Rev. Microbiol. 9, 532-541. doi: 10.1038/nrmicro2595

Ventura, C. V., Maia, M., Bravo-Filho, V., Góis, A. L., Belfort, R., Dick, G., et al. (2016). Zika virus in Brazil and macular atrophy in a child with microcephaly. Lancet 387:228. doi: 10.1016/S0140-6736(16)00006-4

Venturi, G., Zammarchi, L., Fortuna, C., Remoli, M. E., Benedetti, E., Fiorentini, C., et al. (2016). An autochthonous case of Zika due to possible sexual transmission, Florence, Italy, 2014. Euro Surveill. 21. doi: 10.2807/15607917.ES.2016.21.8.30148

Wang, L., Valderramos, S. G., Wu, A., Ouyang, S., Li, C., Brasil, P., et al. (2016). From mosquitos to humans: genetic evolution of Zika Virus. Cell Host Microbe 19, 561-565. doi: 10.1016/j.chom.2016.04.006

Weaver, S. C., Costa, F., Garcia-Blanco, M. A., Ko, A. I., Ribeiro, G. S., Saade, G., et al. (2016). Zika virus: history, emergence, biology, and prospects for control. Antiviral Res. 130, 69-80. doi: 10.1016/j.antiviral.2016.03.010

Wong, P.-S. J., Li, M. I., Chong, C.-S., Ng, L.-C., and Tan, C.-H. (2013). Aedes (Stegomyia) albopictus (Skuse): a potential vector of Zika virus in Singapore. PLoS Negl. Trop. Dis. 7:e2348. doi: 10.1371/journal.pntd.0002348

Yakob, L., Kucharski, A., Hue, S., and Edmunds, W. J. (2016). Low risk of a sexually-transmitted Zika virus outbreak. Lancet. Infect. Dis. 16, 1100-1102. doi: 10.1016/\$1473-3099(16)30324-3

Zanluca, C., de Melo, V. C. A., Mosimann, A. L. P., dos Santos, G. I. V., dos Santos, C. N. D., and Luz, K. (2015). First report of autochthonous transmission of Zika virus in Brazil. Mem. Inst. Oswaldo Cruz 110, 569-572. doi: 10.1590/007402760150192

Zhang, Y., Chen, W., Wong, G., Bi, Y., Yan, J., Sun, Y., et al. (2016). Highly diversified Zika viruses imported to China, 2016. Protein Cell 7, 461-464. doi: 10.1007/s13238-016-0274-5

Conflict of Interest Statement: The authors declare that the research was conducted in the absence of any commercial or financial relationships that could be construed as a potential conflict of interest.

Copyright (C) 2016 Fajardo, Cristina and Moreno. This is an open-access article distributed under the terms of the Creative Commons Attribution License (CC BY). The use, distribution or reproduction in other forums is permitted, provided the original author(s) or licensor are credited and that the original publication in this journal is cited, in accordance with accepted academic practice. No use, distribution or reproduction is permitted which does not comply with these terms. 